\title{
SEISMIC ANALYSIS OF THE GARMROOD EMBANKMENT DAM WITH ASPHALTIC CONCRETE CORE
}

\author{
Siamak Feizi-Khankandi ${ }^{\text {i) }}$, Abbas Ghalandarzadeh ${ }^{\text {ii) }}$, \\ Ali Asghar Mirghasemi ${ }^{\text {iii) }}$ and KaAre Hoeg ${ }^{\text {iv }}$
}

\begin{abstract}
The seismic behaviour of asphaltic concrete core dam under earthquake loads has been studied. The study consists of three parts; element tests on asphalt concrete, numerical analysis and some model tests. In the first part, a series of triaxial monotonic and cyclic tests were performed at the Norwegian Geotechnical Institute (NGI)'s laboratory to determine the geotechnical parameters of asphalt concrete. Then, numerical analyses were carried out for Garmrood dam in Iran with a height of $110 \mathrm{~m}$. The different stages of construction and impounding were analyzed using a hyperbolic stress-strain model. The dynamic analysis was then performed using two different models; nonlinear elasto-plastic material model and an equivalent linear method followed by the Newmark approach to estimate the permanent displacements. Finally, some 1-g model shaking table tests were performed on a typical rockfill dam to have a qualitative picture of the modes of seismic behaviour of an asphaltic concrete core rockfill dam. Element tests result shows that the asphaltic concrete is resistant to earthquake excitations and the earthquake has to be very strong to cause any detrimental cracking or material degradation of the properties of a ductile asphaltic concrete. In addition, the obtained results from numerical analysis and model tests show the appropriate response of the dam during and after earthquake caused shaking.
\end{abstract}

Key words: asphalt concrete core, seismic analysis, shaking table test (IGC: H4/M3)

\section{INTRODUCTION}

The sealing of earth and rockfill dams by means of asphalt concrete cores has attained importance throughout the world. So far, more than 80 asphalt concrete core dams have been constructed. This type of dam has proved to be one of the best options when considering construction costs, the value of water stored during construction, and durability to serve weather conditions during the construction period. The most important engineering properties of the asphalt concrete used in hydraulic structures are workability during placing and compaction, impermeability, flexibility and ductility to avoid cracking as a result of unfavourable field stress and deformation conditions. In regions with cold and rainy weather, construction of this kind of dam is much easier than earth core dams. For many years, monitoring of these dams has indicated their good behaviour during construction and operation (Creegan and Monismith, 1996; Hoeg, 1993; Hoeg et al., 2007; ICOLD, 1992). However, so far there is a little information about the behaviour of asphalt concrete dams subjected to seismic loads. There are only a few published documents that provide infor- mation on the behaviour of asphalt concrete, used as impervious water barriers in dams, during and after earthquake shaking. In Japan, the thin upstream facing is more prevalent than using asphalt concrete as an interior core. However, with respect to water barrier construction requirements and requirements to the engineering properties of the asphalt concrete used, the central core has several advantages (Hoeg, 2005):

1. The upstream facing is exposed to weathering, sun radiation, oxidation and significant temperature variations above the reservoir water level.

2. The post cyclic permanent slope deformations due to earthquake shaking will have relatively little effect on a central core, but cause deflection, possibly tension and shear in an upstream facing.

3. The upstream facing has no lateral stress confinement above the reservoir water level. Thus, cracking is much less likely in an interior core than in an upstream unconfined facing.

However, if cracking or other damage occurs to the upstream facing, it may be exposed and repaired by lowering the reservoir level. It is more difficult to repair any cracks in asphalt concrete core dams. The present study

i) Ph.D., School of Civil Eng., Faculty of Engineering, University of Tehran, Iran.

ii) Assistant Professor, ditto (aghaland@ut.ac.ir).

iii) Associate Professor, ditto.

iv) Professor, Norwegian Geotechnical Institute (NGI) and University of Oslo, Norway.

The manuscript for this paper was received for review on December 27, 2007; approved on December 23, 2008.

Written discussions on this paper should be submitted before November 1, 2009 to the Japanese Geotechnical Society, 4-38-2, Sengoku, Bunkyo-ku, Tokyo 112-0011, Japan. Upon request the closing date may be extended one month. 
consists of three different parts. At first, experimental element tests were carried out on asphalt concrete to investigate the material behaviour during monotonic and cyclic loading. In the second part, numerical analyses were performed for the Garmrood dam, Iran with the height of $110 \mathrm{~m}$, using the finite difference code, FLAC. Finally, model shaking table tests were performed for a typical rockfill dam with as asphalt core to obtain a qualitative picture of the behaviour during cyclic loading.

\section{Previous Numerical Studies}

Valstad et al. (1991) analyzed the Storvatn dam located in Norway using a Newmark approach to derive the earthquake induced permanent displacements. They concluded that the permanent shear displacements of the dam due to severe shaking may become large enough to cause the thin asphalt core to be sheared off in its top portion.

Meintjes and Jones (1999) and Gurdil (1999) analyzed the Ceres dam in South Africa and Kopru dam in Turkey, respectively. They concluded that, based on the predicted behaviour of the dam, the asphalt concrete core dam was safe.

Ghanooni and Mahin-roosta (2002) and FeiziKhankandi et al. (2004) performed dynamic analysis of a typical asphaltic concrete core rockfill dam using both 2-D and 3-D analyses. They concluded that, based on nonlinear analyses, the top part of the core will experience some tensile stresses, but will be smaller than the asphalt concrete strength.

\section{Previous Experimental Work}

The first research in the field of investigating the seismic behaviour of asphaltic concrete core dams was performed by Breth and Schwab (1973). Their study was based on finite element analyses of a dam with a height of $180 \mathrm{~m}$. They devised an interesting set up to impose computed cyclic horizontal stresses on representative elements of the asphaltic concrete core. They concluded that the cyclic earthquake loads did not change the structure and the strength of the asphalt concrete, which essentially is like an elastic material.

Wang (2005) reported a series of cyclic loading tests on triaxial specimens of asphaltic concrete material. $\mathrm{He}$ showed that there was no sign of cracking or degradation of the asphalt concrete samples. Nakamura et al. (2004) carried out some laboratory tests to investigate the engineering material behaviour and based on their tests, a new mixture with title Superflex-phalt was introduced. Salemi (2005) performed numerical and experimental tests for Meyjaran dam in Iran with the height of $60 \mathrm{~m}$. Also, the small scale physical models of asphalt core dams were tested on centrifuge under impact loads. She concluded that her numerical analysis corresponds well with the data recorded in the model tests. She mentioned that the asphalt-concrete core behaves safely under a very severe earthquake.

\section{EXPERIMENTAL WORK ON ASPHALT CONCRETE}

To obtain the material parameters for asphalt concrete, a series of monotonic and cyclic triaxial tests were performed (Feizi-Khankandi et al., 2008).

\section{Preparation of the Asphalt Concrete Specimens}

In order to investigate the stress-strain behaviour of asphalt concrete under static and dynamic loads, monotonic and triaxial tests were performed. Thirty specimens were prepared and then tested with MTS equipment at the NGI laboratory. The specimens were prepared based on the Standardized Marshal Method. The grain size distribution of the sand and gravel in the asphalt concrete mix were complied with Fuller's equation (Hoeg, 1993):

$$
P_{\mathrm{i}}=100\left(\frac{d_{\mathrm{i}}}{\mathrm{d}_{\max }}\right)^{0.41} \%
$$

where, $P_{\mathrm{i}}$ is the percent by weight smaller than the equivalent grain size dimension $d_{\mathrm{i}}$. Based on the Marshal test results, the value of 7.0 percent by weight of bitumen was selected for the mix. The laboratory triaxial specimens were prepared in a mould with a diameter of $100 \mathrm{~mm}$ and a height of $200 \mathrm{~mm}$.

\section{Monotonic Triaxial Tests}

Triaxial monotonic compression tests were conducted to study the stress-strain-strength behaviour of asphalt concrete materials (Feizi-Khankandi et al., 2008). Six monotonic tests were performed at different confining pressures (Table 1). All tests were continued to a very large axial strain (about 20\%). At that stage, the specimens had a pronounced barrel shape and were seriously cracked. During the test, the amount of axial stress, axial strain and volumetric strain were recorded by the electronic sensors used for this purpose. Figure 1 shows the value of deviator stress versus axial strain for imposed confining pressures $(250,500$ and $1000 \mathrm{kPa})$. Shear modulus for static analysis is estimated using stress-strain curves as shown in Fig. 1. As it is clear in this figure, after 0.01 axial strains, the curves tend to have more or less non-linear form. In addition, the specimens' behaviour in all monotonic tests can be assumed somehow linear at strains less than $1 \%$. Therefore the shear modulus at 0.01 axial strains is introduced as elastic modulus in static analysis. For this reason, equivalent Young secant modulus was derived from the initial stage of the curve up to an

Table 1. Results of monotonic triaxial tests on asphalt concrete

\begin{tabular}{c|c|c|c|c|c}
\hline $\begin{array}{c}\text { Test } \\
\text { No. }\end{array}$ & $\begin{array}{c}\sigma_{3} \\
(\mathrm{kPa})\end{array}$ & $\begin{array}{c}E \\
(\mathrm{MPa})\end{array}$ & $\begin{array}{c}\left(\sigma_{1}-\sigma_{3}\right)_{\text {failure }} \\
(\mathrm{kPa})\end{array}$ & $\begin{array}{c}\text { Temperature } \\
\left({ }^{\circ} \mathrm{C}\right)\end{array}$ & $\begin{array}{c}\text { (Axial strain) } \\
\text { at failure (\%) }\end{array}$ \\
\hline T1 & 250 & 135 & 2522 & & 5.5 \\
T2 & 250 & 110 & 2197 & & 5.5 \\
T3 & 500 & 150 & 3129 & 5 & 6 \\
T4 & 500 & 160 & 3332 & & 6 \\
T5 & 1000 & 150 & 3879 & & 15 \\
T6 & 1000 & 150 & 3793 & & 15 \\
\hline
\end{tabular}




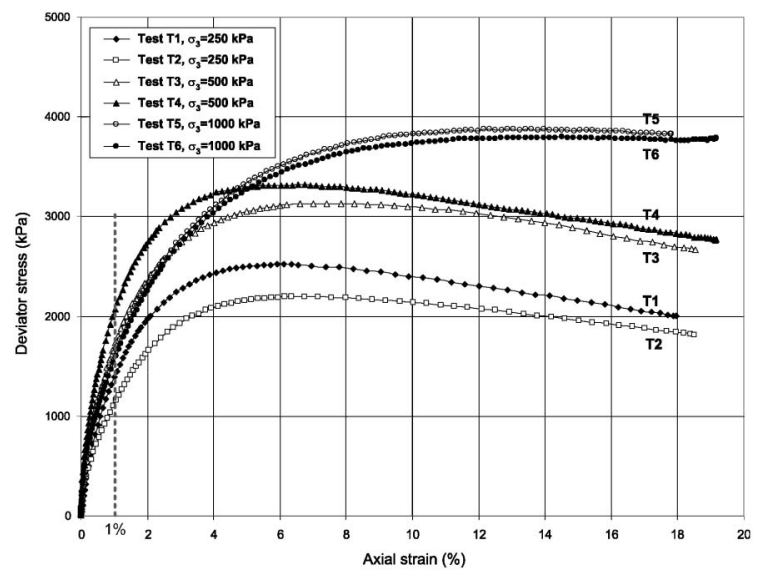

Fig. 1. Deviator stress- axial strain curves

axial strain of $1 \%$ (Feizi-Khankandi et al., 2008). Table 1 presents the results for monotonic triaxial tests. For confining pressures of 250 to $1000 \mathrm{kPa}$, the range of the secant modulus is between $110 \mathrm{MPa}$ and $150 \mathrm{MPa}$.

\section{Cyclic Triaxial Tests}

Twenty- four cyclic triaxial tests were carried out in this research (Feizi-Khankandi et al., 2008). Specimens with rubber membranes were placed in the triaxial cell and then subjected to a confining pressure. In the duration of 12 hours, the temperature gradually reached a predefined value. Then they were loaded under initial isotropic conditions $\left(k_{\mathrm{c}}=\left(\sigma_{1} / \sigma_{3}\right)=1.0\right)$ and anisotropic conditions $\left(K_{\mathrm{c}}\right.$ $=\left(\sigma_{1} / \sigma_{3}\right)=2.0$ and 3.0). The confining pressure was varied from $85 \mathrm{kPa}$ to $500 \mathrm{kPa}$. As the behaviour of the asphaltic concrete core near the top of the dam is of most concern when it is subjected to the cyclic loads of earthquake, this range of confining pressure was selected. All tests were performed at two different temperatures, $T=$ $5^{\circ} \mathrm{C}$ and $T=18^{\circ} \mathrm{C}$. These temperatures were chosen from the temperature monitoring of the dams (Dunnicliff, 1996). The MTS system was scheduled to control the number of cycles. For all specimens, the number of cycles applied at a given load level was set to 50. This number of cycles corresponds to a loading induced by an earthquake with the magnitude of 7.5 in the Richter scale (Kramer, 1996). However, for investigation of the fatigue behaviour, thousands of cyclic loads were imposed to some of the specimens. Based on the recorded information, hysteresis loops were plotted for the first, fiftieth, hundredth and thousandth cycles in different tests. The upper part of the shear stress-axial strain hysteresis curves (such as Fig. 2 ) is used to calculate the shear modulus. Obtained results show that the shear modulus increases from $1.5 \mathrm{GPa}$ in the isotropic condition to nearly $4.0 \mathrm{GPa}$ for anisotropic state with anisotropy coefficient of $K_{\mathrm{c}}=3.0$, at a low temperature of $T=5^{\circ} \mathrm{C}$. For the higher temperature $(T=$ $18^{\circ} \mathrm{C}$ ), the value of shear modulus decreased to half or less as much as the mentioned values. While it is observed that in the isotropic condition and low temperature, the confining pressure does not have a significant effect on the shear modulus, its effect increases with the increase of

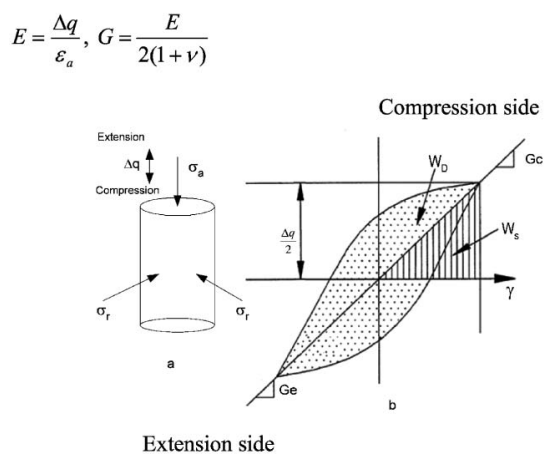

Fig. 2. Cyclic triaxial test; (a) Loads on asphalt concrete specimen and (b) Interpretation

anisotropy and temperature (Fig. 3).

By the following equation, the damping ratio $(D)$ is calculated as (Fig. 2):

$$
D=\frac{1}{4 \pi} \frac{W_{\mathrm{D}}}{W_{\mathrm{S}}} \times 100(\%)
$$

where, $W_{\mathrm{D}}$ is the damping energy in a single loading cycle and $W_{\mathrm{S}}$ is the equivalent elastic energy. The values of damping ratio range between 0.066 and 0.30 .

Figures 3 and 4 present the effect of different parameters such as confining pressure, anisotropy and temperature on the shear modulus and damping ratio. For example in Fig. 3(a), at a constant temperature and anisotropy coefficient, the higher the values of confining pressure, the higher the amount of shear modulus. Comparison between Figs. 3(a) and 3(d) (or Figs. 3(b) and 3(e)) shows that at a high level of anisotropy such as $K_{\mathrm{c}}=$ 3.0 , the effect of confining pressure is more distinct. It can also be seen that the higher anisotropy coefficient causes the higher amount of shear modulus.

In comparison with shear modulus, damping ratio is not significantly dependent on the shear strain amplitude (Fig. 4). However, its value increases gradually with the increase of the shear strain level. It is clearly observed that the dependency to strain value is more distinct at a higher temperature of $T=18^{\circ} \mathrm{C}$ than $T=5^{\circ} \mathrm{C}$. In higher temperatures, the maximum damping ratio is higher than that of lower temperature. Because in high temperatures, viscosity of asphalt concrete may cause the material to easily absorb the applied energy. Therefore in a higher temperature, the dissipated energy in a single loading cycle and consequently the damping ratio increases. (FeiziKhankandi et al., 2008).

The fidelity of the results depends on the accuracy of the measurements of both stresses and strains. The obtained results are affected by two sources of error; compliance and bedding error. In the present study, errors due to apparatus compliance were evaluated with reasonable certainty by careful calibration laboratory. On the other hand, to decrease the effect of bedding error, the surface of specimens was cut and polished with very high accuracy (Feizi-Khankandi et al., 2008).

The results presented above are used as static and dynamic properties for asphalt concrete in the numerical 

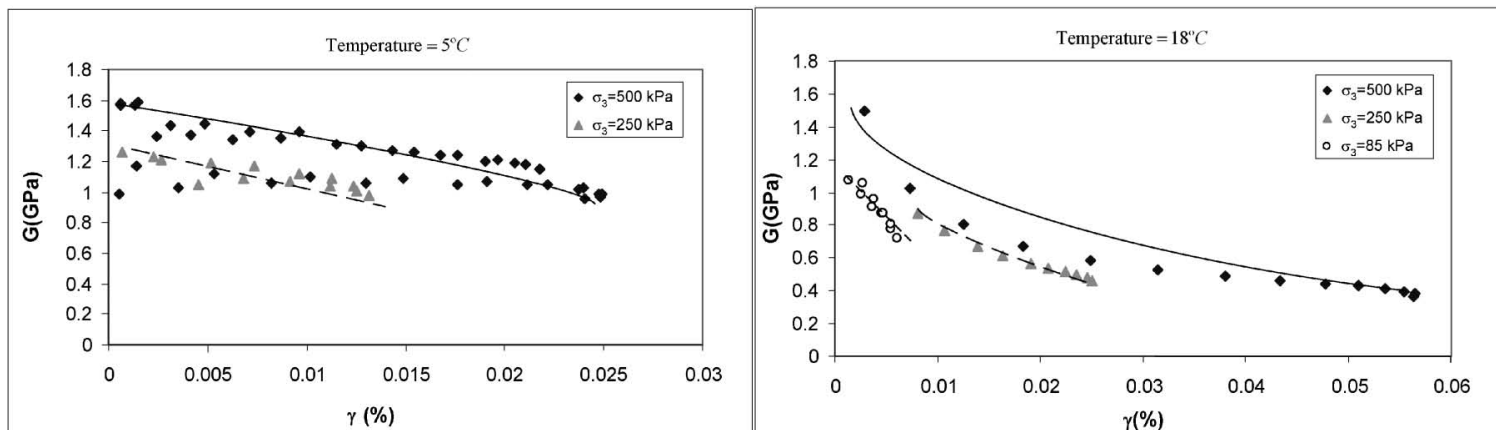

(a) $\mathrm{Kc}=1.0$

(b) $\mathrm{Kc}=1.0$

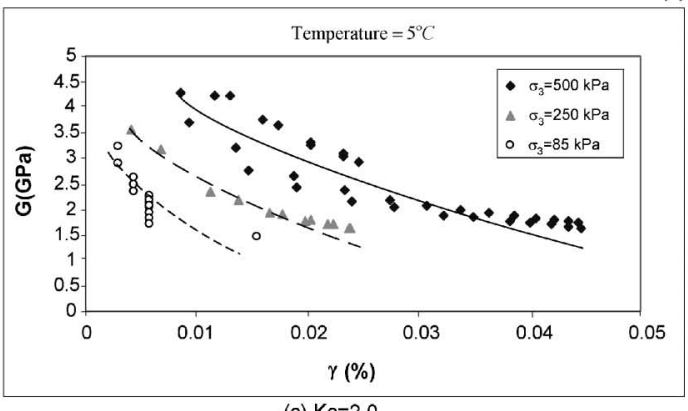

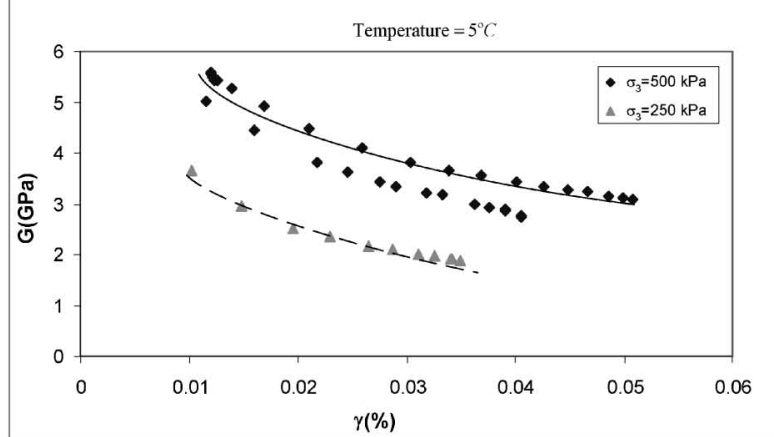

(d) $\mathrm{Kc}=3.0$

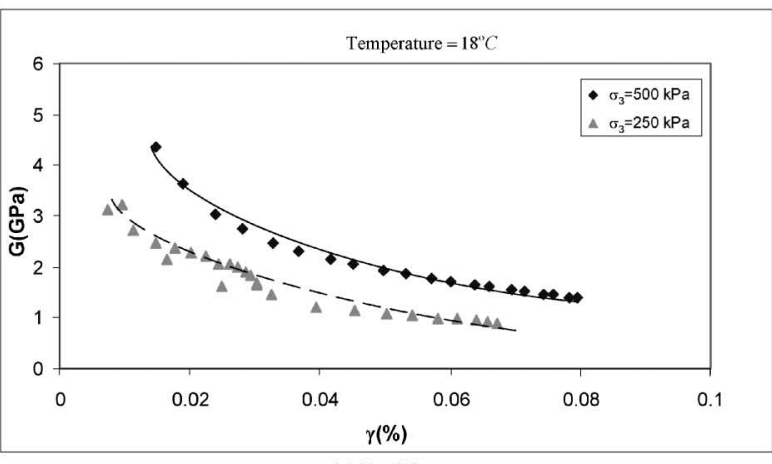

(e) $\mathrm{Kc}=3.0$

Fig. 3. Effects of $\sigma_{3}$ and $K_{\mathrm{c}}$ on strain-dependent modulus at two different temperatures of $5^{\circ} \mathrm{C}$ and $18^{\circ} \mathrm{C}$
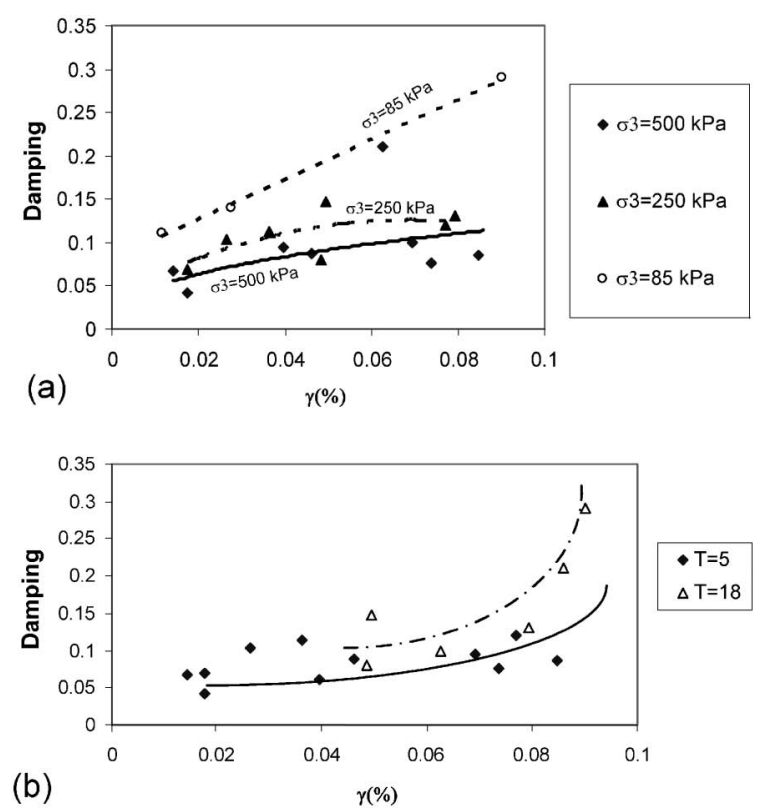

Fig. 4. Effects of $\sigma_{3}$ and temperature on strain-dependent damping ratio analyses.

\section{SEISMO-TECTONIC FEATURES OF THE GARMROOD ASPHALT CORE DAM}

The Garmrood dam is to be located near the city of Babol, north of Iran. The dam is built to exploit a large potential for power generation, irrigation and flood control. After the completion of the dam, the power plant will have a rated capacity of $300 \mathrm{MW}$ and the storage capacity of the reservoir is equal to $270 \mathrm{Mm}^{3}$. Garmrood dam site is located close to the Caspian Sea and the Alborz Mountain and lies within a very seismic region where some major earthquakes have been observed. Figure 5 shows a cross section of the dam. The dam height is $110 \mathrm{~m}$, and the vertical asphalt concrete core is 1 $\mathrm{m}$ wide with transition zones on the upstream and downstream sides. The outer slopes of the dam are 1:1.8 upstream and 1:1.6 downstream. Three borrow areas provide the required material for the dam body. Rockfill with maximum size of $500 \mathrm{~mm}$, dry density of $2000 \mathrm{~kg}$ / $\mathrm{m}^{3}$ and $3 \sim 10 \%$ passing sieve number 200 are considered 


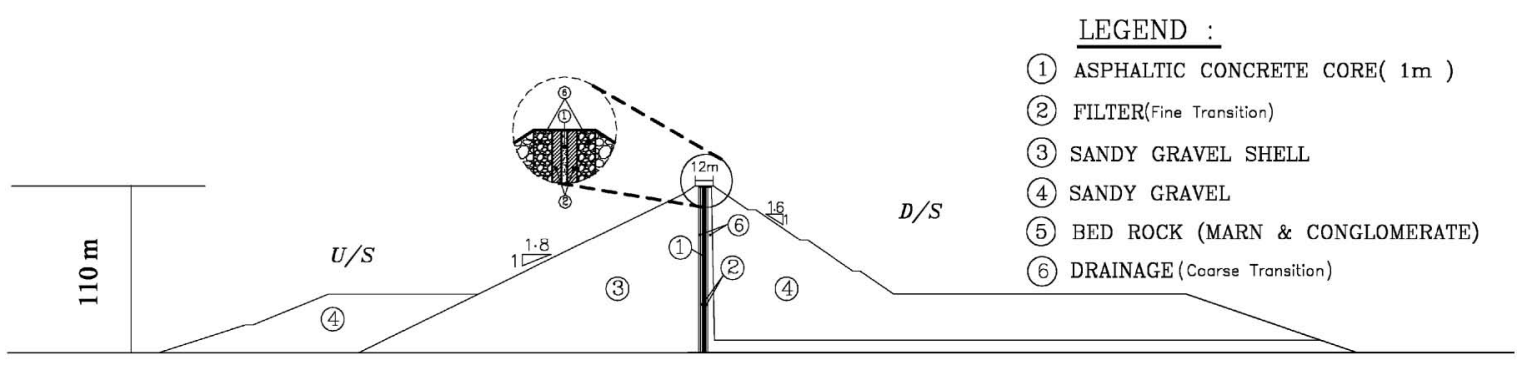

(5)

Fig. 5. Cross section of the Garmrood dam

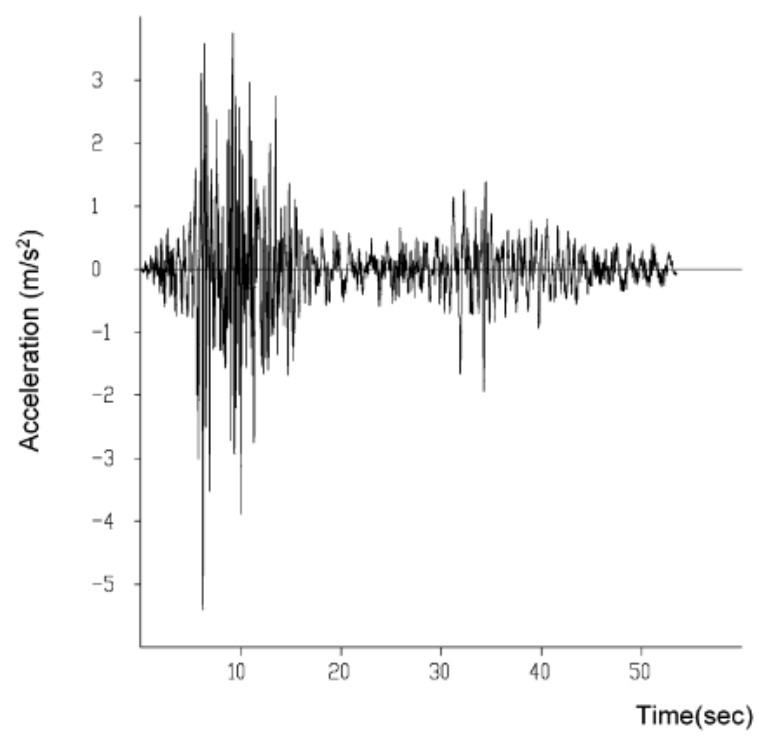

Fig. 6. Input acceleration time history for dynamic analysis

for the upstream shell and with maximum size of $300 \mathrm{~mm}$ for the downstream shell.

The whole region of the dam site has been subjected to a strong tectonism and is one of the most active seismic areas in Asia. The Nesa time history, which had a magnitude of 7.5 on the Richter scale, was selected as the input bedrock motion for the analyses. The horizontal component of the earthquake was scaled to a peak ground acceleration of $0.54 \mathrm{~g}$. Figure 6 shows the acceleration history of input motion.

\section{Dam Body and Foundation Materials Properties}

To determine the material parameter for the rockfill gravel and sand, triaxial tests have been performed. The laboratory triaxial specimens were prepared in a mould with a diameter of $150 \mathrm{~mm}$ and a height of $300 \mathrm{~mm}$ with moisture content of $5 \%$. To obtain a certain density in the laboratory, a certain weight of soil was placed into a mold having a known volume. A tamper system was used for this purpose. The suitable number of tamping to achieve a certain density was obtained by the trial and error method.

The tests were performed at three confining pressures of 200,400 and $800 \mathrm{kPa}$. Figure 7 shows the typical results for the deviator stress and volume change versus axial strain. Based on the tests results, the parameters of Duncan-Chang (1970) and Mohr-Coulomb models were determined.

The dam is placed in a U-shape valley underlain by a marl-conglomerate foundation. This marl-conglomerate is classified as a weak rock. For this material, direct shear tests have been performed. Table 2 shows the selected parameters from the performed tests (Mahab-Ghodss, 2004).

\section{NUMBERICAL ANALYSES}

In this research, 2D static and dynamic analyses based on the assumption of plane-strain conditions were carried out. This assumption is strictly valid only for infinitely long dams subjected to a "synchronous" base excitation. The computations were performed using the FLAC code (Itasca, 1998). The hyperbolic stress-strain model (Duncan and Chang, 1970) was developed for modeling of stage construction of the geo-structures such as dams and thus this model is only used for modeling the dam body material at the static analysis (end of construction and impounding stages) in the current study. However, this model has some weaknesses that make it not-suitable for dynamic analysis. For example the model is not capable of simulating hysteresis stress-strain curve, especially in the unloading stage. Therefore the Mohr-Coulomb model is used for the earthquake loading section while is more compatible with both parts of loading and unloading stages in hysteresis loops.

Figure 8 shows the cross section of the grid created for Garmrood dam analyses. For accurate representation of wave transmission in the model, the element sizes have been selected small enough to satisfy the following criteria expected by Kuhlemeyer and Lysmer (1973): $\Delta l \leq(\lambda / 10)$ where $\lambda$ is the wave length associated with the highest frequency component that contains appreciable energy and $l$ is the length of element. The maximum element size in direction of dam height is $2 \mathrm{~m}$ and in other directions it varies up to $5 \mathrm{~m}$. Therefore, the frequency up to $20 \mathrm{~Hz}$ can be transmitted through the asphalt core. Movement in the vertical direction for right and left 

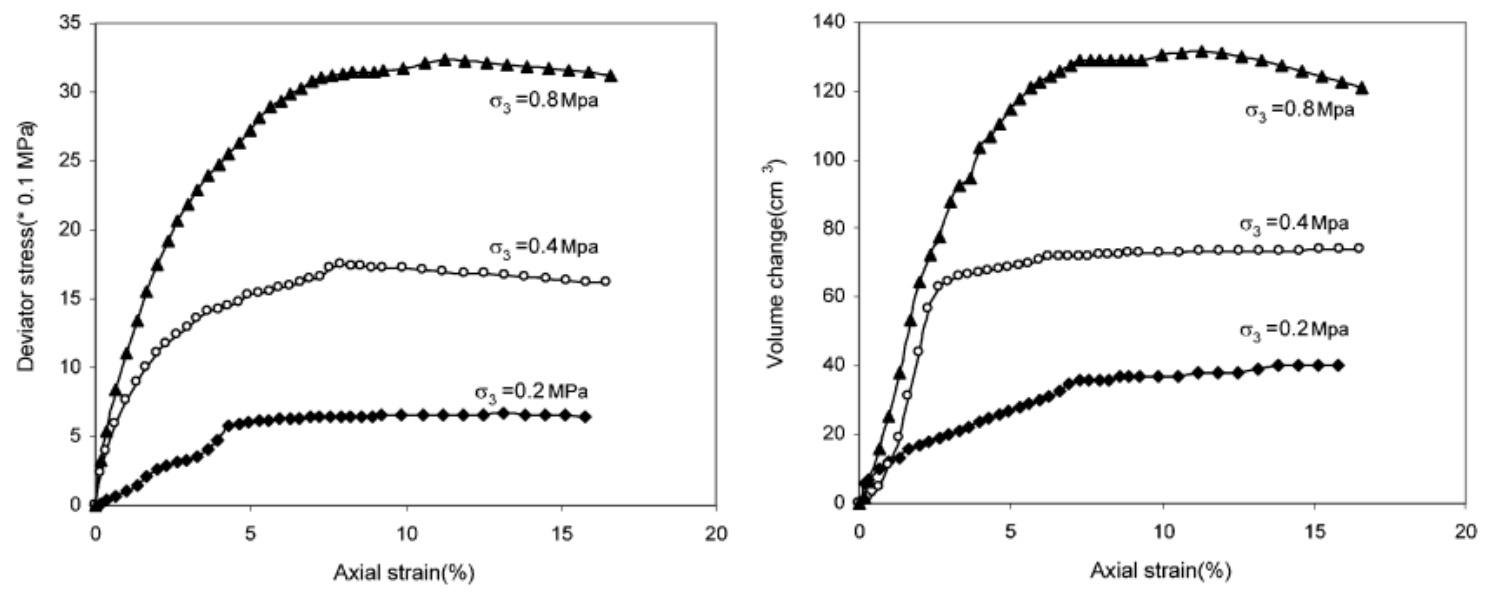

Fig. 7. Triaxial tests results for the shell material

Table 2. Geotechnical parameters used in numerical analyses I: Static analyses

A: hyperbolic model parameters for shell and transition zones

\begin{tabular}{c|c|c|c|c|c|c|c|c|c|c|c|c}
\hline Zone & Material & $\gamma\left(\mathrm{kN} / \mathrm{m}^{3}\right)$ & $K_{\mathrm{i}}$ & $K_{\mathrm{b}}$ & $K_{\text {ur }}$ & $n$ & $m$ & $R_{\mathrm{f}}$ & $C(\mathrm{~Pa})$ & $\phi$ & $\Delta \phi$ & $K(\mathrm{~cm} / \mathrm{s})$ \\
\hline 1 & Transition & 19 & 200 & 150 & 400 & 0.4 & 0.5 & 0.7 & 0.0 & 35 & 3 & $1 \mathrm{E}-4$ \\
\hline 2 & Shell & 20 & 400 & 250 & 700 & 0.65 & 0.5 & 0.7 & 0.0 & 40 & 4.5 & $1 \mathrm{E}-3$ \\
\hline
\end{tabular}

B: Mohr-Coulomb model parameters for foundation and asphalt concrete

\begin{tabular}{c|c|c|c|c|c|c|c}
\hline Zone & Material & $\gamma\left(\mathrm{kN} / \mathrm{m}^{3}\right)$ & $\mathrm{E}(\mathrm{MPa})$ & $v$ & $C(\mathrm{MPa})$ & $\phi$ & $K(\mathrm{~cm} / \mathrm{s})$ \\
\hline 3 & Foundation & 19 & 300 & 0.3 & 0.0 & 30 & $5 \mathrm{E}-5$ \\
\hline 4 & Asphaltic Core & 24.2 & 150 & 0.45 & 1.0 & 17 & $1 \mathrm{E}-8$ \\
\hline
\end{tabular}

II: Dynamic analyses

\begin{tabular}{|c|c|c|c|c|}
\hline & Asphalt concrete & Transitions & Shell & Foundation \\
\hline$\gamma\left(\mathrm{t} / \mathrm{m}^{2}\right)$ & 2.42 & 1.9 & 2.0 & 19 \\
\hline$n$ & 0.03 & 0.2 & 0.3 & 0.2 \\
\hline$v$ & 0.45 & 0.3 & .25 & 0.3 \\
\hline$G_{\max }(\mathrm{GPa})$ & $\begin{array}{c}2.3 \\
\text { (Section “Cyclic Triaxial Tests”) }\end{array}$ & $8400 \frac{(2.17-e)^{2}}{1+e}\left(\sigma_{0}^{\prime}\right)^{0.6}$ & $13000 \frac{(2.17-e)^{2}}{1+e}\left(\sigma_{0}^{\prime}\right)^{0.55}$ & $19800 \times\left(\sigma_{\circ}^{\prime}\right)^{0.5}$ \\
\hline Damping (\%) & $\begin{array}{c}25 \\
\text { (Section “'Cyclic Triaxial Tests") }\end{array}$ & 4 & 5 & 4 \\
\hline
\end{tabular}

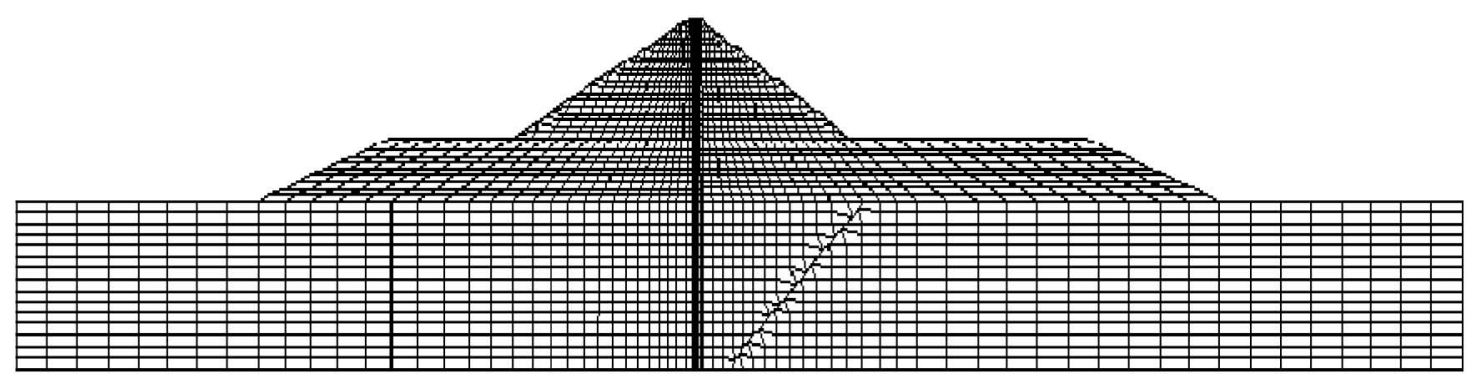

Fig. 8. Generated mesh for the Garmrood dam 
boundaries of the foundation and also movement in any direction at lowest level of the foundation are restricted for the model.

The maximum dam cross section was selected for the finite difference analysis, and a $100 \mathrm{~m}$ depth of the foundation was modeled down to an assumed rigid horizontal boundary. The left vertical boundary was located $200 \mathrm{~m}$ upstream of the dam toe and the right vertical boundary $200 \mathrm{~m}$ downstream.

\section{Static Analyses}

The static analyses were carried out for various stages including construction and impounding. The hyperbolic stress-strain model (Duncan and Chang, 1970) was used for the dam body and the Mohr-Coulomb model for the foundation and asphalt core. Table 2(I) presents the material properties for static analyses.

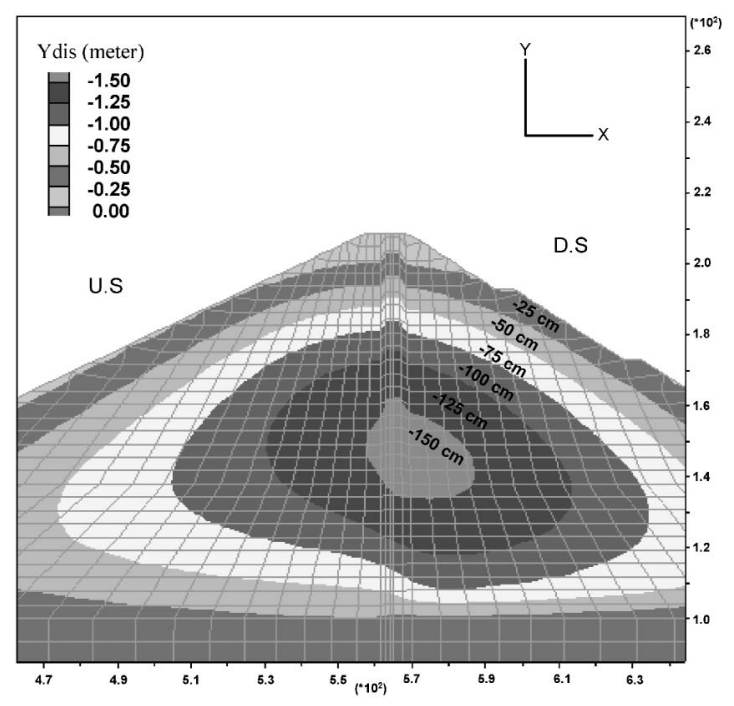

Fig. 9. Settlement contours at end of construction

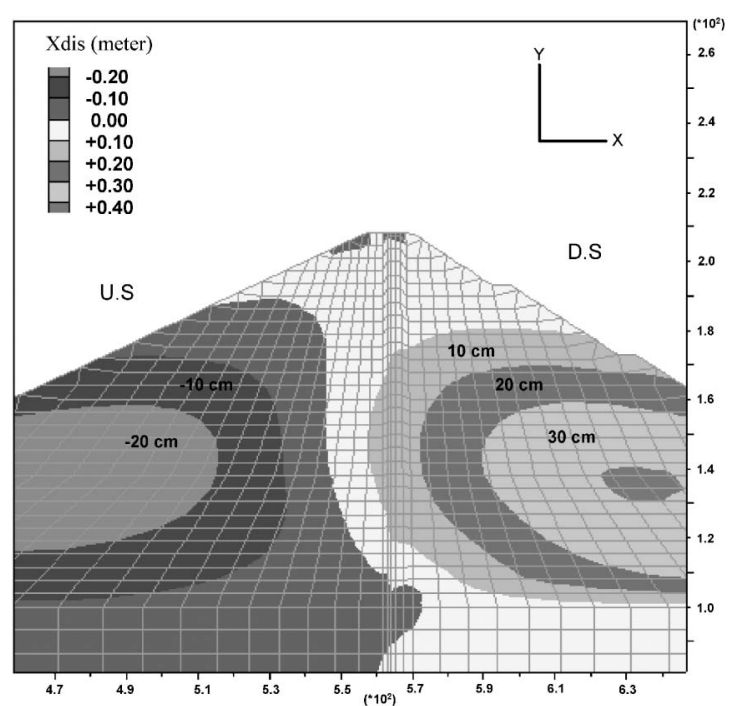

Fig. 10. Horizontal displacement contours at end of construction

\section{End of Construction}

The analyses were performed using staged construction in 29 layers. The only loading of the dam body is the weight of the materials. Figures 9 and 10 show the vertical and horizontal displacement contours. The maximum settlement at end of construction occurs at mid-height of the dam and slightly downstream of the dam axis. The maximum settlement is nearly $1.5 \mathrm{~m}$. The maximum horizontal displacement is $25 \mathrm{~cm}$ with almost symmetric at displacement contours.

\section{Impounding Stage}

The water level is increased to a height of $103 \mathrm{~m}$ above the base in three stages. During impounding, a hydrostatic force acts on the surface of the virtually impervious asphalt core.

Vertical and horizontal displacement contours due to the impounding are plotted in Figs. 11 and 12. The maxi-

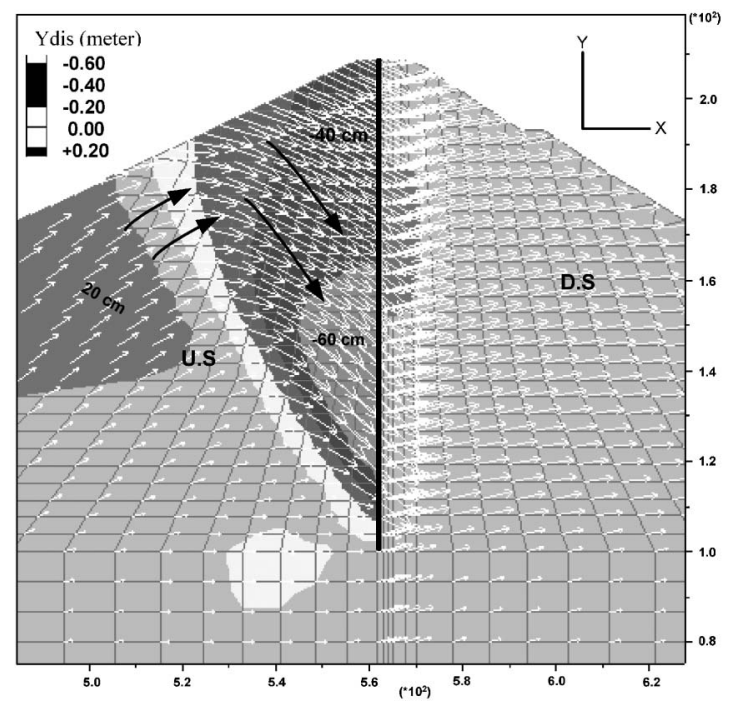

Fig. 11. Vertical displacement contours due to impounding only

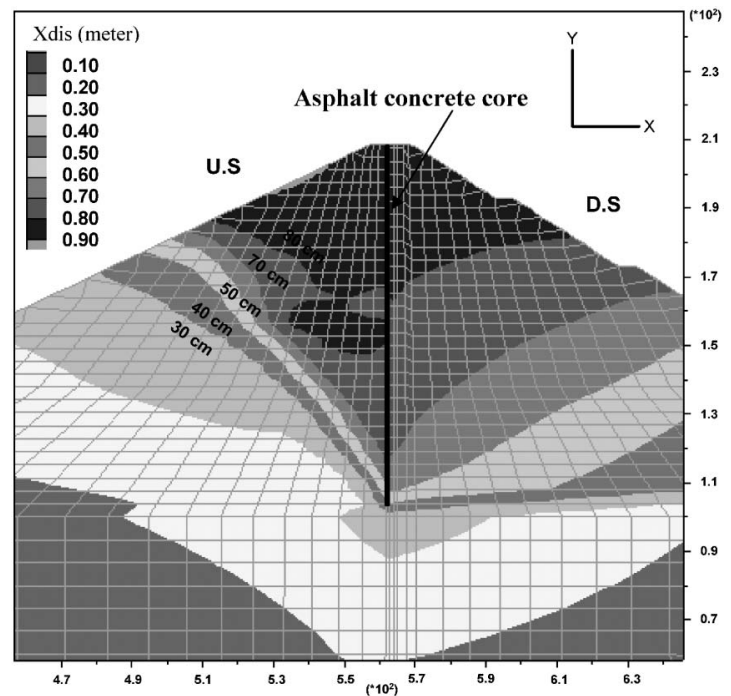

Fig. 12. Horizontal displacement contours due to impounding only 
mum settlement (after impounding only) is observed to be $60 \mathrm{~cm}$ in a region upstream of the core. The displacement vectors are shown in Fig. 11. Submergence of the upstream shell causes the buoyancy forces to give a maximum upward displacement of $25 \mathrm{~cm}$ inside the upstream shell. The upward displacement does not usually occur in real embankment dams despite most numerical analysis may show some swelling deformations in this part. The main reason of this occurrence could be the weakness of used models for the shell material in numerical analysis. These models cannot simulate collapse settlement due to saturation. Moreover, by increasing the water level in reservoir, the effective stresses decrease and therefore, the shell material shows upward movements. In real cases, collapse settlement, which it is not considered in the numerical analysis, could cause the settlement of the upstream shell. However since the main emphasis of this study is the investigation of seismic behaviour of asphalt core, all displacements during the construction and impounding stages were set to zero and thus the upward deformation of the upstream shell calculated in static analysis prior to the seismic one may not affect the final results.

The reservoir loading causes bending of the asphalt core to the downstream side. Since, the effective horizontal stresses at the upstream side decrease, the US-shell materials settle in the core region. Figure 13 shows the pore pressure contours after the impounding. It is observed that because of very low permeability of asphalt concrete, the amount of pore pressure suddenly falls inside the asphalt concrete core. Figure 14 shows the effective horizontal stress contour due to impounding. Saturation of the upstream shell causes an increase of the total stresses. However, the values of effective horizontal stresses on the downstream side increased more than those on the upstream side. Therefore, the entire dam body moves to the downstream side.

\section{Dynamic Analysis}

All dynamic analyses were performed at full-reservoir condition. In this paper, the dynamic analyses were carried out using two different models; the non-linear model utilizing FLAC program and the equivalent linear model combined with the Newmark approach to compute permanent shear displacements of the slopes (Newmark, 1965).

The material model for asphalt concrete, rockfill and gravel used in the non-linear elasto-plastic dynamic analysis is a strain-hardening/softening model based on the Mohr-Coulomb model. It has the possibility that the cohesion, and friction, and dilation angles and tensile strength may increase or decrease after the onset of plastic yielding. The frictional hardening relation used in this research is the one proposed by Vermeer and de Borst (1984):

$$
\begin{aligned}
& \sin \varphi_{\mathrm{m}}=2 \frac{\sqrt{\varepsilon_{\mathrm{p}} \varepsilon_{\mathrm{f}}}}{\varepsilon_{\mathrm{p}}+\varepsilon_{\mathrm{f}}} \quad \sin \varphi \text { for } \varepsilon_{\mathrm{p}} \leq \varepsilon_{\mathrm{f}} \\
& \sin \varphi_{\mathrm{m}}=\sin \varphi \text { for } \varepsilon_{\mathrm{p}}>\varepsilon_{\mathrm{f}}
\end{aligned}
$$

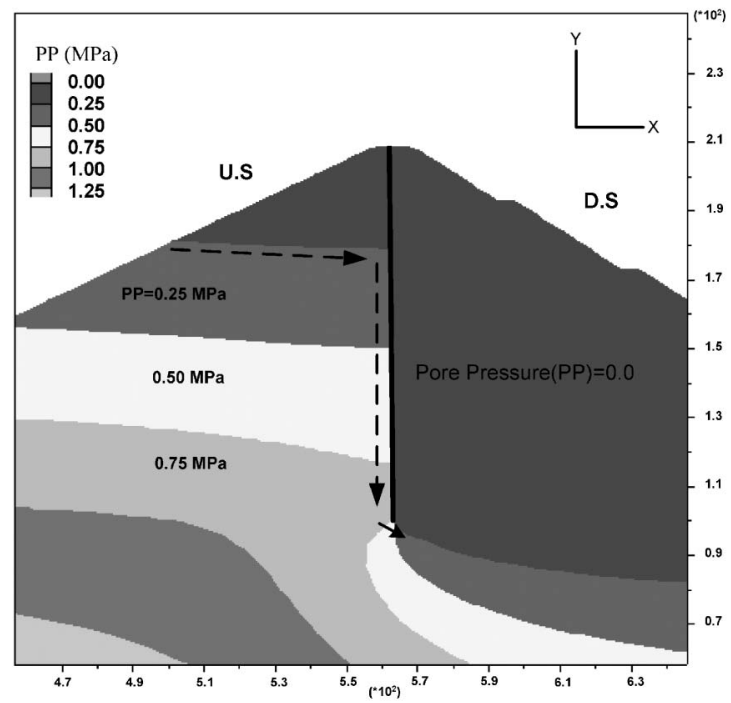

Fig. 13. Pore pressure contours due to impounding only

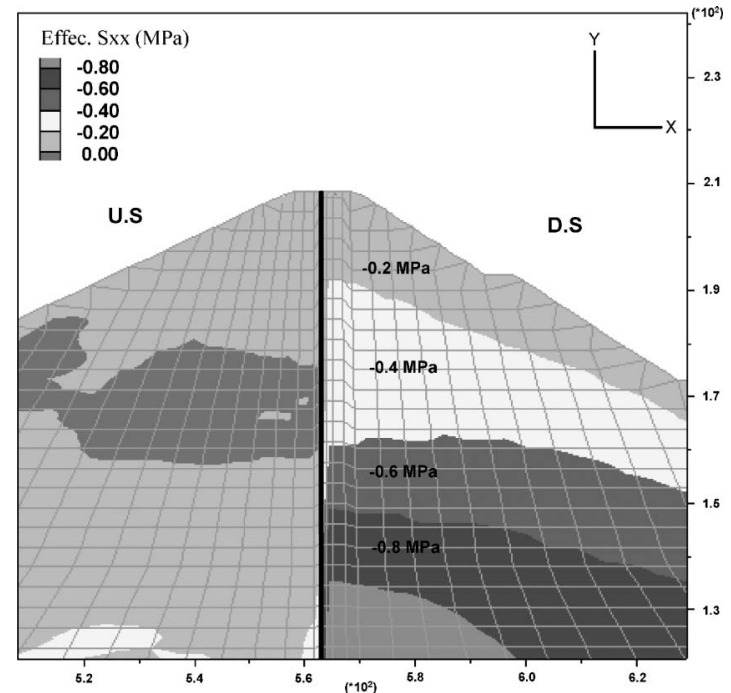

Fig. 14. Effective horizontal stress due to impounding only

where $\varphi=$ peak friction angle,

$\varphi_{\mathrm{m}}=$ mobilized friction angle,

$\varepsilon_{\mathrm{p}}=$ plastic shear strain,

$\varepsilon_{\mathrm{f}}=$ plastic shear strain at peak friction angle.

Peak friction angles for the rockfill and gravel and for the asphaltic core are selected $40^{\circ}, 35^{\circ}$ and $17^{\circ}$, respectively. For the equivalent linear model, the following parameters are used (Figs. 3 and 15):

- $G_{\max }$

- Poisson ratio

- $G-\gamma$ and $D-\gamma$ curves

In the rockfill and gravel materials, the small strain shear modulus, $G_{\max }$ is estimated based on some empirical relations. The shear modulus is a function of effective octahedral stress:

$$
\sigma_{\mathrm{o}}^{\prime}=\left(\sigma_{1}^{\prime}+\sigma_{2}^{\prime}+\sigma_{3}^{\prime}\right) / 3
$$

For rockfill, $G_{\max }$ is used as below (Kokusho and Esashi, 


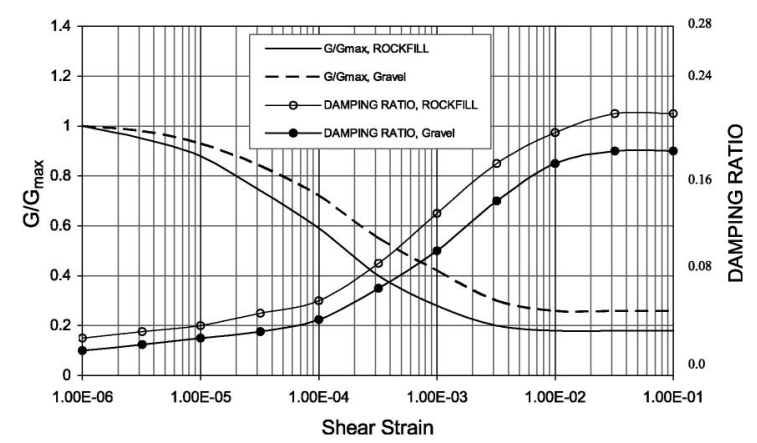

Fig. 15. Modulus reduction curves and variation of damping ratio of materials

1981):

$$
G_{\max }=13000 \frac{(2.17-e)^{2}}{1+e}\left(\sigma_{0}^{\prime}\right)^{0.55}
$$

And for gravel (Kokusho and Esashi, 1981):

$$
G_{\max }=8400 \frac{(2.17-e)^{2}}{1+e}\left(\sigma_{0}^{\prime}\right)^{0.6}
$$

The non-linear behaviour of rockfill and gravel materials is presented in the form of $G-\gamma$ and $D-\gamma$ curves in Fig. 15 where $G$ and $D$ are the secant shear modulus and damping ratio, respectively and $\gamma$ is the shear strain. The curves are based on the studies by Kokusho and Esashi (1981) and Seed and Idriss (1970). The determination of the asphalt concrete properties is described in EXPERIMENTAL WORK ON ASPHALT CONCRETE, Fig. 3 and Table 2(II).

\section{Results of Dynamic Analyses}

Using the models discussed in DYNAMIC ANALYSIS, dynamic response of the dam in the steady seepage condition was analyzed. Because of the high permeability in the rockfill and gravel, no generation of excess pore water pressure was assumed. In the following sections, results of the non-linear and equivalent linear methods are presented.

\section{Non-linear Dynamic Analysis}

The non-linear cyclic stress-strain behaviour of the materials can be represented by non-linear models that follow the actual stress-strain path during cyclic loading. The elasto-plastic Mohr-Coulomb model was used for all the materials incorporated in the dam body. This model can produce curves of apparent damping and modulus versus cyclic strain as well as path dependent, permanent deformations caused by the earthquake loading. For these elasto-plastic models, the yield functions define the stress combination for which plastic flow takes place. The plastic flow formulation in FLAC rests on the basic assumption from the plasticity theory that the total strain increment may be decomposed into elastic and plastic parts, with only the elastic part contributing to the stress increment according to the elastic law. In addition, both plastic and elastic strain increments are taken to be coaxi-

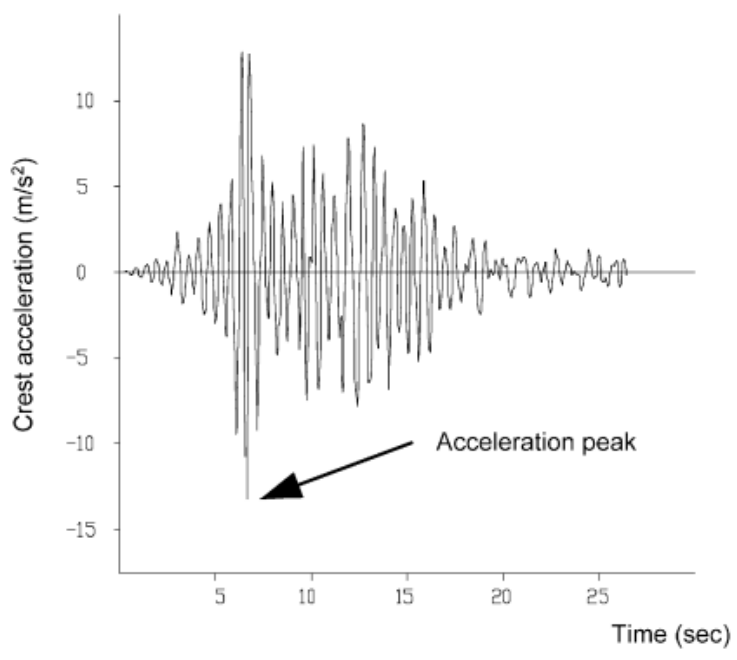

Fig. 16. Time history of acceleration at the crest

al with the current principal axes of the stresses (Varmeer and de Borst, 1984). For the Mohr-Coulomb model, a shear yield function and a non-associated shear flow rule is used.

In addition, the failure envelope for the model is characterized by a tensile yield function. The failure envelope for the model corresponds to a Mohr-Coulomb criterion with tension cutoff (tensile yield function). A tensile yield function is defined as the following relation:

$$
f^{\mathrm{t}}=\sigma^{\mathrm{t}}-\sigma_{3}
$$

Where $\sigma^{\mathrm{t}}$ is the tensile strength.

For a material with friction $\phi \neq 0$, the tensile strength of the material cannot exceed the value $\sigma_{\text {max }}^{\mathrm{t}}$ given by the following relation:

$$
\sigma_{\max }^{\mathrm{t}}=\frac{c}{\tan \phi}
$$

During dynamic analysis, the Mohr-Coulomb model was used for all parts of the dam body. Therefore all defined Mohr-Coulomb functions in FLAC were applied to the structure during seismic analysis. For this model, the created stresses cannot get above failure line and the difference between the created force and the reprehensive force on the yield surface is converted to a permanent displacement. The non-linear dynamic analysis was performed by using the acceleration time histories that indicate the Maximum Credible Level (MCL) of the earthquake at the site ( $a_{\max }=0.54 \mathrm{~g}$, Fig. 6). The computed acceleration response of the crest is shown in Fig. 16. The calculated maximum acceleration at the crest is $1.40 \mathrm{~g}$.

The value of amplification factor can be calculated as what follows (Gazetas et al., 1992):

$$
A F=\frac{a_{\text {crest }}}{a_{\text {base }}}=\frac{1.40}{0.54}=2.59
$$

Figure 17 shows the vertical displacement contours and the deformed shape of the asphalt core after the shaking. The maximum settlement occurs near the dam crest inside the upstream shell, and its value is nearly $1.5 \mathrm{~m}$ which is 


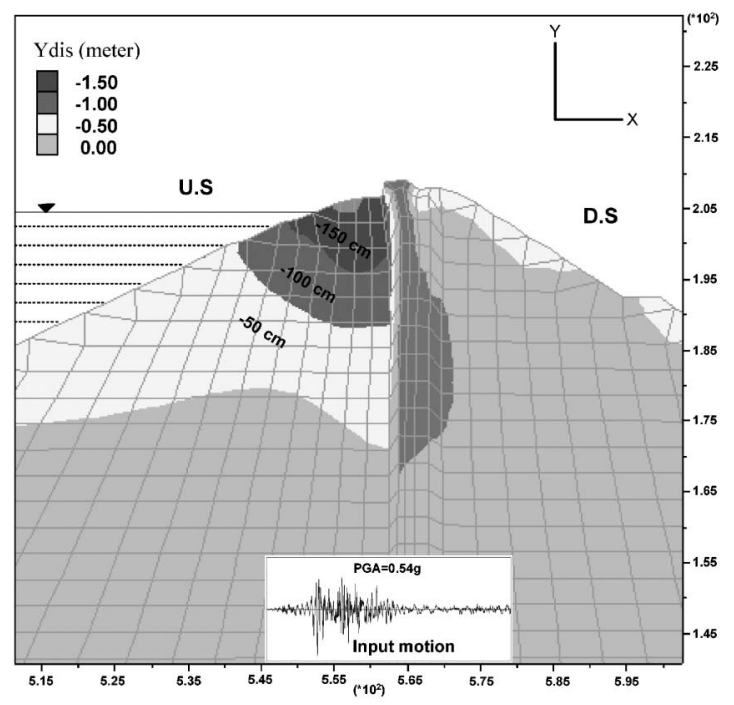

Fig. 17. Settlement contours after the dynamic shaking

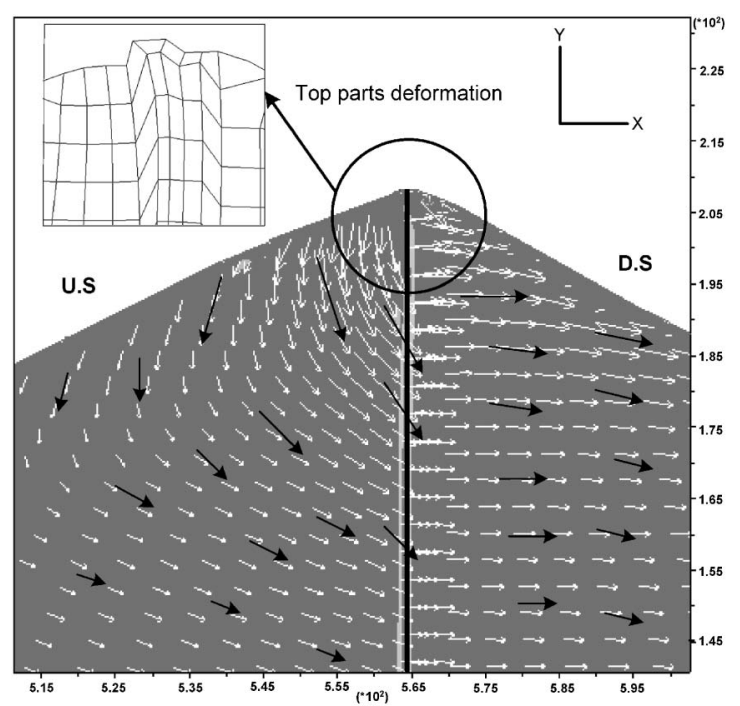

Fig. 18. Displacement vectors of the embankment and core after the dynamic shaking

about $1.4 \%$ of the maximum dam height. Figure 18 shows the permanent displacement vectors after earthquake loading. The largest vectors are seen near the crest at the upstream side.

The magnitudes of permanent strain and stress on the $45^{\circ}$-plane and shape of the core deformations at different times of loading were calculated and plotted in Figs. 19, 20 and 21, respectively. These figures show the variation of stress and permanent strain in the asphalt core over the dam height after earthquake shaking. In other words, the calculated deformations are the residual deformations. It can be seen that the top part of the core experiences some tensile stresses. However, the value of this tensile stress is much lower than that of asphalt concrete. The induced permanent shear strains are small within the core, with a maximum value less than $0.5 \%$ near the crest.

There is a significant relative settlement between the

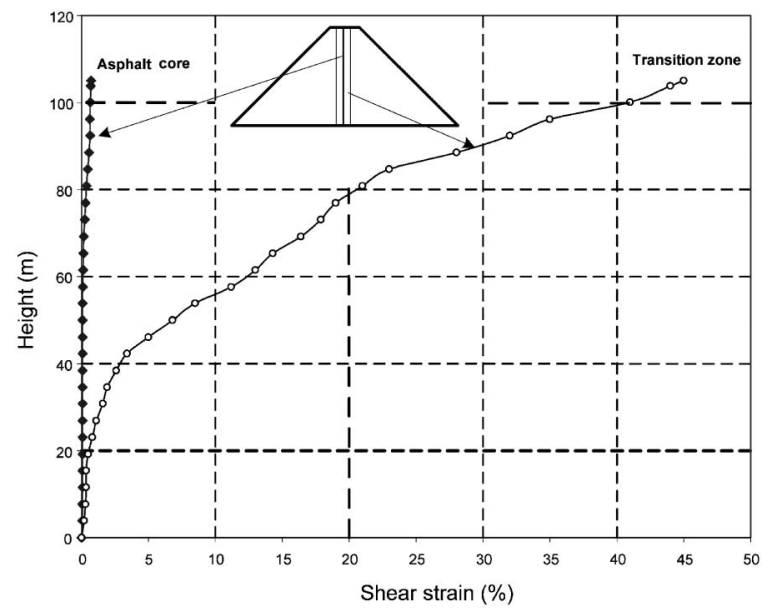

Fig. 19. permanent strain in the core and transition zones after dynamic loading

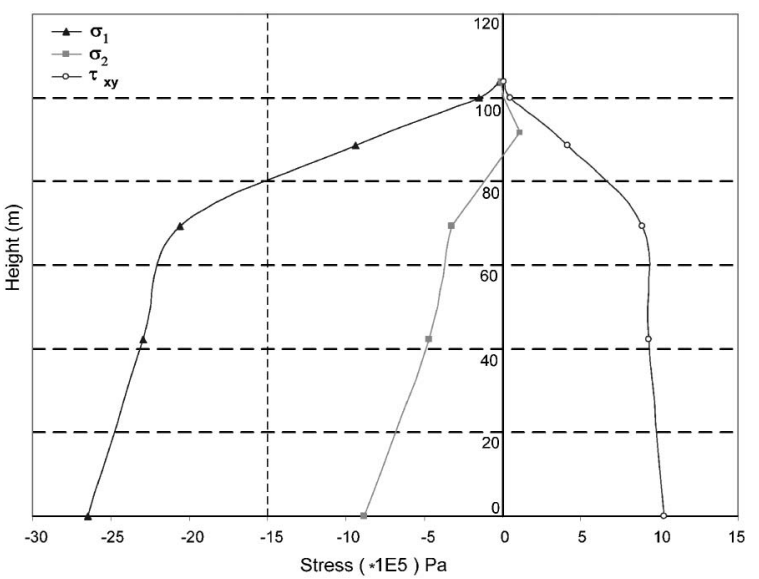

Fig. 20. Principal and shear stresses in the asphalt concrete core after the dynamic shaking

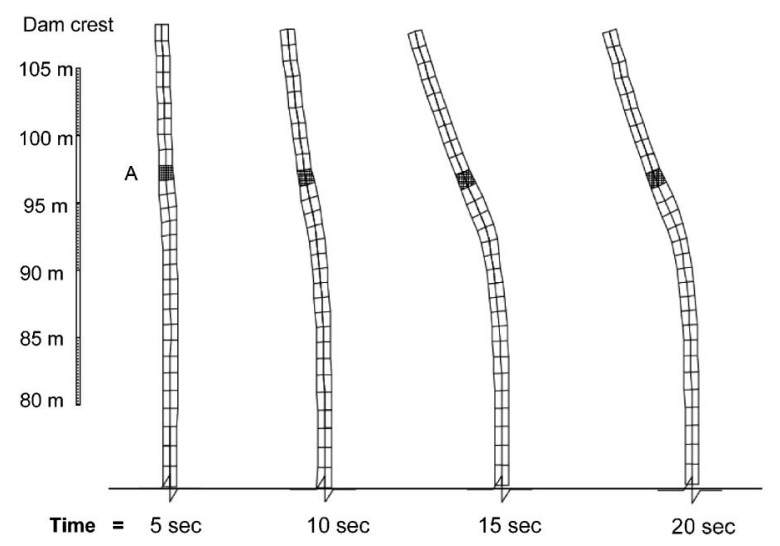

Fig. 21. shape of the core deformations at different times of loading

upstream and downstream transition and the asphalt concrete core (Figs. 17, 18 and 19). The value of permanent shear strain in the transition layers on either side of the core is very large, whereas the asphalt concrete core experiences small deformations and remains in the elastic 
range.

\section{Equivalent Linear Analysis}

A dynamic analysis can also be done by using the equivalent linear method. The effect of material nonlinearity is considered using this iterative method where the damping ratio increases and shear modulus decreases due to the increase in shear strain. A set of moduli and damping ratios was initially assumed and a series of linear analyses was conducted, with each calculation using material moduli and damping ratios compatible with the levels of shear strain in the previous step. In this approach, non-linearity is modeled, but the permanent displacement of the slope after the dynamic analysis is zero, because of material model linearity. However, the Newmark method (1965) can be used to estimate the permanent shear displacements induced by the earthquake.

Table 2, Figs. 3 and 15 show the input information for the analysis. The maximum crest acceleration computed is $1.57 \mathrm{~g}$. This is somewhat more than that computed by the non-linear analyses described in NON-LINEAR DYNAMIC ANALYSIS (1.40 g).

The dynamic results of the equivalent linear method were then used to derive the average seismic coefficient for critical slip surfaces at different heights of the embankment. A set of potential slip surfaces was defined as shown in Fig. 22.

The model tests observation presented in SHAKING TABLE TESTS and the nonlinear analyses (Figs. 17 and 18 ) indicate that the formation of the SUi surface is more probable than the SCi surface. However, the calculation of permanent displacements was performed for all sets of the selected slip surfaces.

To determine the average acceleration history for any point on a trial sliding surface, a new sub-routine was developed in the FLAC code. The critical seismic coefficient $\left(k_{\mathrm{y}}\right)$ for each sliding mass is defined where the safety factor equals to 1.0. Using the FLAC code in combination with the mentioned sub-routine, the acceleration history for each trial sliding mass (SUi, SCi and SDi) was determined. The permanent displacements were then determined by the double integration method from the acceler- ation history, as was suggested by Newmark (1965). Although the method is very simple and neglects the dynamic response of the material above the potential slip surface, it provides reasonable estimate of the permanent displacements (Kramer et al., 1997).

Table 3 gives the results of the analysis. A maximum permanent displacement of $81 \mathrm{~cm}$ was calculated for a sliding mass in the upper part of the dam cutting the upstream shell at the maximum water level. The slip surface passing through the asphalt core is not a critical mass because of asphalt concrete properties.

The equivalent linear model shows smaller permanent displacements and larger amplification factor compared to the non-linear method. Permanent displacement and peak crest acceleration are calculated in equivalent linear model to be $81 \mathrm{~cm}$ and $1.57 \mathrm{~g}$, respectively whereas these amounts are $150 \mathrm{~cm}$ and $1.40 \mathrm{~g}$ in non-linear model. While it is not defined any yield surface in the equivalent linear model in comparison with nonlinear model, the sliding block could resonance till any level. However this occurrence is controlled by critical seismic coefficient $\left(k_{\mathrm{c}}\right)$ in nonlinear model. The non-linear method is more appropriately modeling the response of the dam than that of the equivalent linear method. In summary, the numerical analyses show that the Garmrood dam with the central asphalt concrete core behaves safely during and after earthquake loading. The asphalt core deforms and

Table 3. Results of Newmark slip surface method

\begin{tabular}{c|c|c|c|c|c|c|c|c|c}
\hline Slip surface & $\mathrm{SC} 1$ & $\mathrm{SC} 2$ & $\mathrm{SC} 3$ & $\mathrm{SD} 1$ & $\mathrm{SD} 2$ & $\mathrm{SD} 3$ & $\mathrm{SU} 1$ & $\mathrm{SU} 2$ & $\mathrm{SU} 3$ \\
\hline$k_{\mathrm{y}}(\mathrm{g})$ & 0.38 & 0.31 & 0.31 & 0.48 & 0.42 & 0.40 & 0.35 & 0.28 & 0.23 \\
\hline$k_{\mathrm{m}}(\mathrm{g})$ & 1.10 & 0.78 & 0.50 & 0.81 & 0.56 & 0.49 & 1.05 & 0.82 & 0.66 \\
\hline $\begin{array}{c}\text { Horizontal Dis. (cm) } \\
\leftarrow\end{array}$ & 41 & 27 & 4.5 & 12 & 2.5 & 0.24 & 55 & 69 & 25 \\
\hline $\begin{array}{c}\text { Displacement } \\
\text { along the U.S } \\
\text { slope surface (cm) } \\
\swarrow\end{array}$ & 48 & 32 & 5.3 & 14 & 2.9 & 0.28 & 64 & 81 & 29 \\
\hline
\end{tabular}

$k_{\mathrm{y}}=$ yield acceleration coefficient

$k_{\mathrm{m}}=$ maximum seismic coefficient

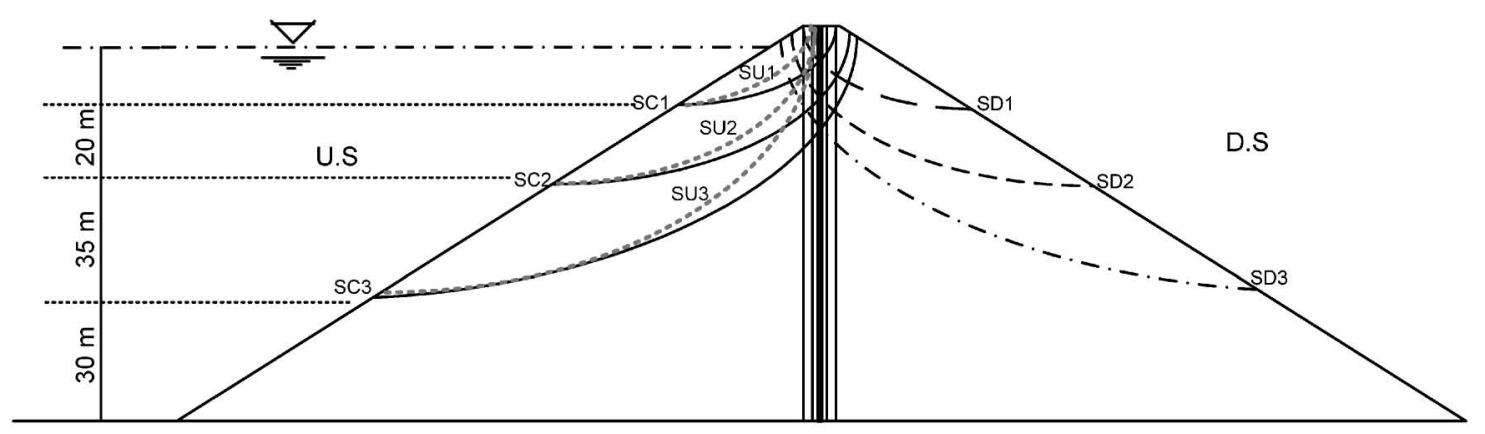

SUi: the upstream slip surface passing inside transition zone (not through asphalt core)

$S C i$ : the upstream slip surface passing through asphalt core

$S D i$ : the downstream slip surface

Fig. 22. Assumed sliding masses used in the Newmark analyses 


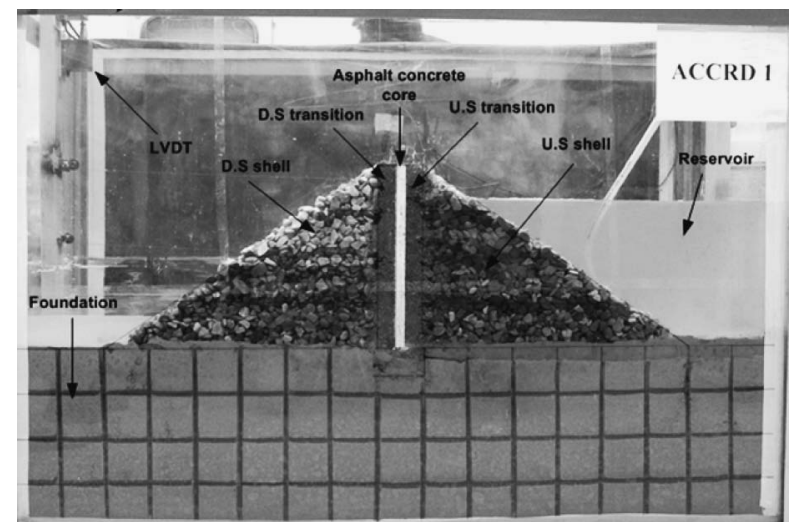

Fig. 23. Rockfill dam model with the asphalt element before dynamic loading

deflects but retains its properties as an impervious element.

\section{SHAKING TABLE TESTS}

Dynamic tests of two-dimensional rockfill dam model with a central impervious asphalt core were conducted using a shaking table at the Soil Mechanic Laboratory, University of Tehran. The model dam with a height of $45 \mathrm{~cm}$ was installed into a shaking table with a length of $1.85 \mathrm{~m}$ and height of $1.2 \mathrm{~m}$. The similitude rules proposed by Iai (1989) for shaking table tests at $1 \mathrm{-g}$ gravitational field were applied for determination of the loading conditions.

For preventing foundation liquefaction during the earthquake loading, the model foundation was compacted to $90 \%$ relative density. After completion of the foundation construction, the asphalt core was built to its full height. Then the materials of the transition and shell zones with the density of $2200 \mathrm{~kg} / \mathrm{m}^{3}$ were built in layers and compacted. For better observation of the mechanism of deformation and tracking the aggregates, colored aggregates were used at different heights of the dam.

Models were excited with horizontal sinusoidal motion, and the frequency response functions of the dam models were obtained. Figure 23 shows the dam model with reservoir inside the shaking table before application of seismic loading.

In shaking table model tests, height of the core was 40 $\mathrm{cm}$. During the shaking and after that, even at a very high input motion, the asphalt core could retain its workability such as impermeability and also there was not any sign of crack on the surface of it. The main occurrence was the differential displacement between the core and transition layers. The maximum displacement in model tests under $0.6 \mathrm{~g}$ and $6 \mathrm{~Hz}$ harmonic input motion with a duration time of 10 seconds was $2 \mathrm{~cm}$. However; it is very complicated to extend the shaking table model results to a real structure directly using similarity rules. It should be noted that the main objective of performing the model tests was to have a qualitative picture of the modes of seismic behaviour for an asphaltic core and observation of stability or failure mechanism of the embankment dam. Since similar numerical analysis with harmonic input is not

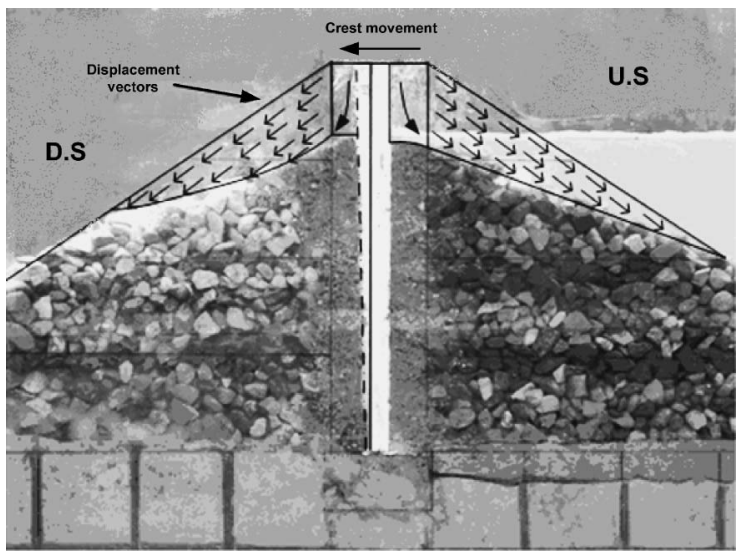

Fig. 24. Deformation of the dam after loading

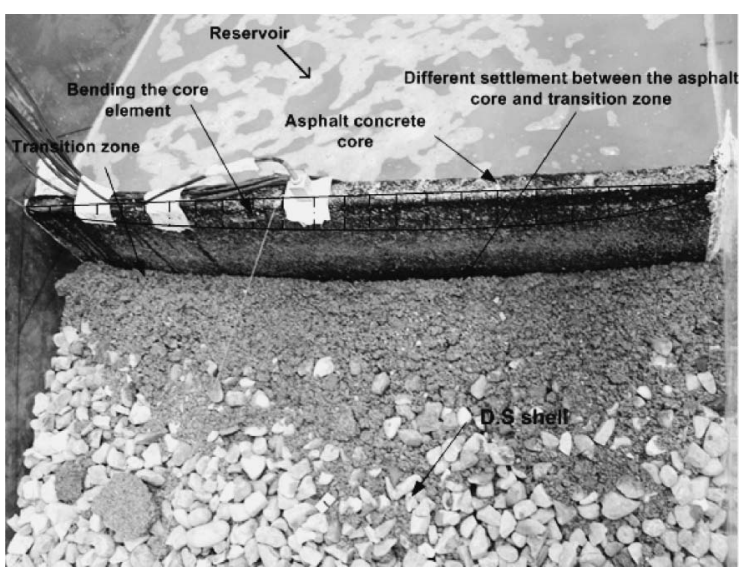

Fig. 25. Relative displacement between the core and transition

done here, it is not possible to quantitatively compare the results of two types of studies. In addition, presented results in dynamic section (RESULTS OF DYNAMIC ANALYSES) for a dam with the height of $110 \mathrm{~m}$ shows that there is no special problem of stability of asphalt concrete core (based on the core displacement and stressstrain level) against earthquake loading.

Acceleration and displacement transducers and pore and total pressure cells at different heights of the core and shell were used to record the dynamic response. The dominant frequency of the seismic input used in the model tests was between 6 and $10 \mathrm{~Hz}$. The excitation amplitude was between $0.10 \mathrm{~g}$ and $0.60 \mathrm{~g}$ in the full reservoir state. A summary from the tests results can be presented as follows:

- Significant deformations occur in the shell and transition zones but little in the concrete core (Figs. 24 and 25). This mechanism confirms the results of the dynamic non-linear analysis (Figs. 17 to 19). No cracks on the core's surface were detected by visual inspection after cyclic loading, even after application of very high excitation amplitude $\left(a_{\max }=0.60 \mathrm{~g}\right)$.

- A slip surface seemed to pass through the transition layer (SUi) continuing inside the shell. This shows that the determination of SUi as a critical slip surface 
in the equivalent linear analysis was appropriate. The observations support the concept of a sliding mode of deformation predicted in the theoretical studies. However, in view of the inadequacy of such small-scale models to reproduce the significant effects of gravity on material behaviour, the results should be interpreted with caution, and only qualitatively.

- Figure 24 shows the shape of deformation of the whole dam. It is observed that the asphalt concrete core deforms to the downstream side. The model test shows similar deformations on both sides of the core, while the numerical analyses show a larger settlement in upstream of the core. The main reason for this difference is the limitation of FLAC constitutive models. The numerical constitutive model does not include all the volumetric changes caused by the shaking. In addition; the hydrodynamic forces are neglected in the FLAC formulation. The large deformation of the shell and transition zones is due to contractive volume change and falling and rolling of rockfill material on surface area. Moreover, in model tests, the effect of boundary conditions (because of the shaking table size) and the amount of confining pressure (that is not real) are the appreciable factors affecting the results. In some of the model tests, with high compaction, the amount of deformation on the upstream side is more than that of on the downstream side, as shown in the numerical analyses.

- A different deformation is seen between the asphalt core and transition layers (Fig. 24). It approves that during earthquake loading, the asphalt core and transition regions deform differently.

\section{SUMMARY AND CONCLUSIONS}

The results obtained from the present study may be summarized as follows:

- During construction, the deformations of the asphalt core are completely dependent on the shell deformations and the thin core wall can not affect the general deformation behaviour of the dam.

- During impounding, the impervious core wall significantly affects the deformation and stress distribution in the embankment.

- During earthquake loading, there is a significant relative vertical settlement between the thin core and the transition zones. The results of non-linear analysis and model tests confirm this behaviour.

- The dynamic non-linear analysis shows that permanent shear strain after earthquake loading is very small inside the asphalt core $(0.5 \%)$ in comparison with that of the transition zones.

- The iterative equivalent linear dynamic analysis gives a somewhat higher acceleration amplification factor than the non-linear elasto-plastic model.

- The equivalents linear model in combination with a Newmark analyses shows somewhat smaller perma- nent displacements than that of non-linear model.

- Both the numerical analyses and the shaking table tests show that the asphalt concrete core does not experience any significant degradation due to the earthquake loading.

This study shows that the Garmrood Dam, as a representative of high dams with central asphalt core, shows satisfactory performance during earthquake loading.

\section{ACKNOWLEDGMENT}

The present research was supported by the Iranian Water Resources Management Organization (IWRMO) and Mahab-Ghodss consulting engineers in Iran, and the contractor Kolo-Veidekke in Norway. The authors appreciate the assistance of laboratory employees at the Norwegian Geotechnical Institute, Kolo-Veidekke and University of Tehran during the experimental work. In addition, the authors would like to thank Dr. Ali Noorzad for his assistance and support during this study.

\section{NOTATION}

The following terms are utilized in this research:

$\gamma$ : shear strain, for triaxial test is calculated as $\gamma=\varepsilon_{1}-$ $\varepsilon_{3}$.

$q$ : deviator stress, is the difference between major and minor principal stresses in a triaxial test.

$v$ : Poisson ratio.

$\sigma_{3}$ : confining pressure, is a pressure applied into the triaxial cell.

$\sigma_{1}$ : axial stress, is applied in the axial direction of the specimen, while lateral stress is applied in the radial direction of the specimen.

$K_{\mathrm{c}}$ : anisotropic stress ratio, is calculated by dividing the axial stress by lateral stress $\left(K_{\mathrm{c}}=\left(\sigma_{1} / \sigma_{3}\right)\right)$.

$G$ : shear modulus, is calculated from hysteresis loops. $G_{\mathrm{c}}$ and $G_{\mathrm{e}}$ are defined for the compression and extension regions inclination, respectively.

$D$ : damping ratio, is carried out from hysteresis loops.

\section{REFERENCES}

1) Breth, H. and Schawab, H. H. (1973): Zur Eignung des asphaltbetons fur die Innendictung von Staudammen, Wassewirtschaft 69, Heft 11, 348-351, Stuttgart, Germany.

2) Creegan, P. and Monismith, C. (1996): Asphaltic Concrete Water Barriers for Embankment Dams, ASCE Press.

3) Duncan, J. M. and Chang, C. Y. (1970): Nonlinear analysis of stress and strain in soils, Journal of Soil Mechanics and Foundation Division, 96(SM5) ASCE.

4) Dunnicliff, J. (1996): Geotechnical Instrumentation for Monitoring Filed Performance, 2nd ed., USA.

5) Feizi-Khankandi, S., Mirghasemi, A. A. and Ghanooni, S. (2004): 3-D seismic analysis of asphaltic concrete core rockfill dams, ICGE Conference, 220-225, UAE.

6) Feizi-Khankandi, S., Mirghasemi, A. A., Ghalandarzadeh, A. and Hoeg, K. (2008): Cyclic triaxial tests on asphalt concrete as a water barrier for embankment dams, Soils and Foundations, 48(3), 319-332.

7) Gazetas, G. and Dakoulas, P. (1992): Seismic analysis and design of rockfill dams: State-of-the-art, Soil Dynamics and Earthquake 
Engineering.

8) Ghanooni, S. and Mahin-roosta, R. (2002): Seismic analysis and design of asphaltic concrete core embankment dams, Journal of Hydropower and Dams, 6, 75-78.

9) Gurdil, A. F. (1999): Seismic behaviour an asphaltic concrete core dams, Ist Symposium on Dam Foundation, Antalya, Turkey.

10) Hoeg, K. (1993): Asphaltic Concrete Cores for Embankment Dams, Norwegian Geotechnical Institute, Oslo, Norway.

11) Hoeg, K. (2005): Earthquake resistance of asphalt concrete cores embankment dams, Norwegian Geotechnical Institute of Technology's Report (20051031-1), Oslo, Norway.

12) Hoeg, K., Valstad, T., Kjaernsli, B. and Ruud, A. M. (2007): Asphalt core embankment dams: recent case studies and researches, Journal of Hydropower and Dams, 13(5), 112-119.

13) Iai, S. (1989): Similitude for shaking table tests on soil-structurefluid model in 1-g gravitational filed, Soils and Foundations, 29(1), 105-118.

14) ICOLD Press $(1982,1992):$ Bituminous Cores for Earth and Rockfill Dams, Bulletins 42 and 84.

15) Itasca Consulting Group (1998): Fast Lagrangian Analysis of Continua, FLAC, Minneapolis, Minnesota, USA.

16) Kokusho, T. and Esashi, Y. (1981): Cyclic triaxial test on sands and coarse materials, Proc. 10th ICSMFE, Stockholm, Sweden.

17) Kramer, S. T. and Smith, W. (1997): Modified Newmark model for seismic displacements of compliant slopes, J. of Geotechnical and Geoenviromental Engineering, (123), 635-643.

18) Kuhlemeyer, R. L. and Lysmer, J. (1973): Finite element method accuracy for wave propagation problems, Journal of Soil Mechan- ics and Foundations, Div. ASCE, 99(SM5), 421-427.

19) Mahab-Ghodss Phase II Report (2004): Garmrood Dam Feasibility Studies, Mahab-Ghodss Archive, Iran.

20) Meintjes, H. A. C. and Jones, G. A. (1999): Dynamic analyses of the new cores dam, Proc. 12th Regional Conference for Africa on $S M G E$, Durban, South Africa.

21) Nakamura, Y., Okumura, T., Narita, K. and Ohne, Y. (2004): Improvement of impervious asphalt mixture for high ductility against earthquake, 4th International Conference on Dam Engineering, 18-20, China.

22) Newmark, N. (1965): Effects of earthquakes on dams and embankments, Geotechnique, 15, 139-160.

23) Salemi, S. (2005): Dynamic behaviour investigation of asphaltic concrete core rockfill dams, PhD Dissertation, IUST University, Iran.

24) Seed, H. B. and Idriss, I. M. (1970): Soil moduli and damping factors for dynamic response analysis, Technical Report No. EERC 75-29, Earthquake Engineering Research Center, University of California, Berkley, USA.

25) Valstad, T., Selness, P. B., Nadim, F. and Aspen, B. (1991): Seismic response of a rockfill dam with an asphaltic concrete core, Journal of Water Power and Dam Construction, 43, 1-6.

26) Vermeer, P. A. and de Borst, R. (1984): Non-associated plasticity for soils, concrete and rock, Heron, 29(3), 1-64, (quoted by Itasca 1998), USA.

27) Wang, W. (2005): Cyclic Tests on Asphalt Concrete, Xi'an University Press, China. 